\section{Nutritional conditions in early life and risk of non-communicable diseases (NCDs) from the perspective of preemptive medicine in perinatal care}

\author{
Hiroaki Itoh, Naohiro Kanayama
}

Department of Obstetrics and Gynecology, Hamamatsu University School of Medicine,
Reprint request to:

Hiroaki Itoh, M.D., Ph.D., Department of Obstetrics and Gynecology, Hamamatsu University School of Medicine, 1-20-1, Handayama, Higashi-ku, Hamamatsu, 341-3192, Japan.

E-mail: hitou-endo@umin.ac.jp

\section{Key words:}

developmental origins of health and diseases (DOHaD), fetal origins of adult disease, fetus, pregnancy, thrifty phenotype

Received: December 11, 2014

Revised: February 3, 2015

Accepted: February 9, 2015

DOI:10.14390/jsshp.3.1

Hamamatsu, Japan

\begin{abstract}
Non-communicable diseases (NCDs) are chronic diseases that are non-infectious and non-transmissible. The World Health Organization (WHO) classifies cardiovascular disorders (myocardial infarction or stroke), diabetes, chronic respiratory diseases, and malignancy as the four major disease types of NCDs. Evidence supporting the influence of various environmental factors in the early developmental period on the risk of developing NCDs in adults has increased recently, leading to the proposal of the developmental origins of health and disease (DOHaD) theory. We reviewed the background of the paradoxical circumstances in which the morbidity of NCDs has rapidly increased in both developing and developed countries in view of distinct prenatal nutritional environments in the context of the DOHaD theory. We also discuss candidates for early interventions and biological samples for identifying biological markers in individuals at high risk of NCDs from the perspective of preemptive medicine in perinatal care.
\end{abstract}

\section{Introduction}

Non-communicable diseases (NCDs) are chronic diseases that are not passed from person to person and generally develop slowly over the course of life. The World Health Organization (WHO) proposed four main types of NCDs, i.e., cardiovascular diseases, diabetes, chronic respiratory diseases, and malignancy, ${ }^{1,2)}$ in which obesity and metabolic syndrome are significantly involved. The WHO estimated that $63 \%$ of global deaths, approximately 36 million, were attributed to NCDs, and indicated that NCDs are expected to exceed communicable, maternal, perinatal, and nutritional diseases as the most common causes of death worldwide by $2030 .{ }^{1,2)}$ The annual number of deaths due to NCDs continues to rise in both developing and developed countries. ${ }^{1-3)}$ The recently developed theory of developmental origins of health and disease $(\mathrm{DOHaD})^{4,5)}$ proposed that nutritional conditions during the fetal, neonatal, and infantile periods are related to the NCD pandemic. ${ }^{6,7)}$ In view of the DOHaD theory, perinatal and neonatal medicine may help in the development of preemptive medicine against the rapid spread of adult NCDs. ${ }^{89}$ ) We herein discuss this possibility, as well as animal studies that support a nutritional imbalance in utero and in early postnatal life as a contributor to the recent NCD pandemic, with a particular focus on obesity and metabolic syndrome.

\section{Developmental Origins of Health and Disease (DOHaD) Theory}

Epidemiological and animal studies revealed a possible association between environmental aggression in the early developmental period and the emergence of chronic diseases in later life. This concept suggests new links of causality and infers the early establishment of metabolic adjustments that determine morbidity throughout life, especially those causatively associated with NCDs, ${ }^{6,7)}$ leading to a new branch of scientific knowledge known as the 'DOHaD' theory. ${ }^{4,10,11)}$ 


\section{Undernourishment in utero and risk of NCDs in later life}

Epidemiological evidence connecting undernourishment in utero and the development of adult metabolic syndrome was initially obtained from victims of the Dutch Hunger Winter in 1944-5 during World War II. The adult and/or senile offspring of women exposed to the famine in gestation were predisposed to NCDs including coronary heart disease, obesity, impaired glucose tolerance, hypertension, an atherogenic lipid profile, disturbed blood coagulation, increased stress responsiveness, microalbuminuria, schizophrenia, and antisocial personality. ${ }^{12-14)}$ Fetal exposure to the Chinese Famine in 1959-61 was associated with a predisposition to hyperglycemia, type 2 diabetes, and metabolic syndrome in adulthood. ${ }^{15,16)}$ The association between fetal exposure to the Chinese Famine and an increased risk of adult metabolic syndrome was stronger among subjects with a Western style diet and/or those who were overweight in adulthood. ${ }^{17)}$

Cohort studies identified a relationship between low birth weight and elevated adiposity in children ${ }^{18,19)}$ as well as adults $;{ }^{20-22}$ however, small babies were not always simply the result of undernourishment in utero.

\section{'Thrifty phenotype' hypothesis}

Among the many mechanistic frameworks that have been proposed to explain the biological basis underlying possible associations between undernourishment in utero and obesity-related metabolic disorders in later life, ${ }^{23)}$ the 'thrifty phenotype' hypothesis by Hales and Barker ${ }^{24)}$ is the most compelling. ${ }^{25,26)}$ They proposed the concept of an adaptive response to fetal undernourishment that optimizes body growth in utero and leads to a permanently altered postnatal metabolic phenotype to match the predicted postnatal conditions of long-lasting poor nutrient supply and enhancing survivability throughout life under the circumstances of starvation $^{24)}$ (Figure 1). Embryonic and/ or fetal 'predictive adaptive responses' 27 ) to suboptimal intrauterine undernourishment may promote permanently enhanced energy economy. This has been referred to as the 'thrifty phenotype'. Regarding the 'matching' aspect of the 'thrifty phenotype' hypothesis, a previous study reported that small babies in Gambia, including those born during a nutritionally-debilitating hunger season, maintained excellent metabolic as well as cardiovascular conditions into adulthood with the complete absence of metabolic syndrome, provided that they retained their frugal lifestyle in rural areas. ${ }^{28)}$

The 'thrifty phenotype' was proposed to only become detrimental when nutrition was more abundant in the postnatal environment than had been expected from

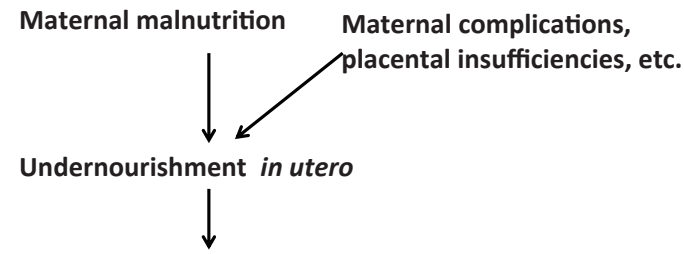

Fetal growth restriction as an adaptation to low energy supply in utero
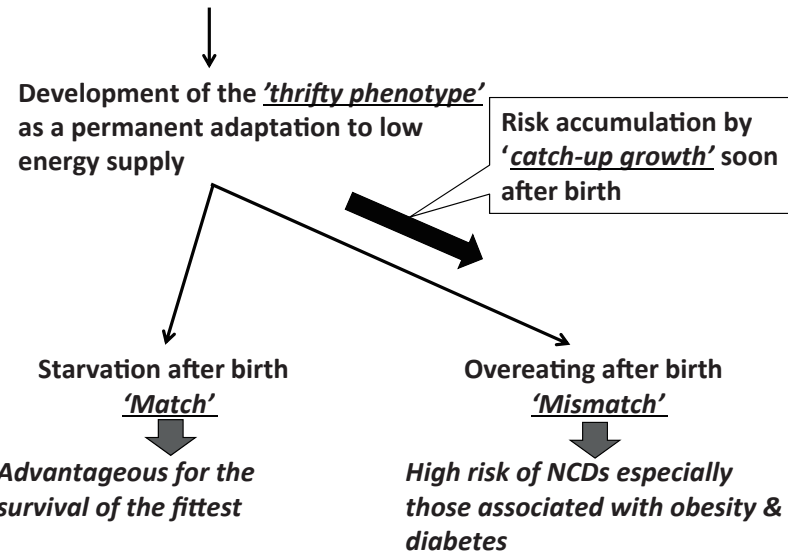

Figure 1. Relationship between undernourishment in utero, the 'thrifty phenotype', 'catch-up growth', and the risk of NCDs.

the prenatal environment of undernourishment because this phenotype for enhanced energy economy may lead to a 'mismatch' to the excess energy supply associated with the modern lifestyle of overeating, thereby predisposing adults to NCDs, especially those associated with obesity and/or type 2 diabetes ${ }^{24-26,29-32)}$ (Figure 1). Developing countries have been undergoing rapid economic improvements over the past few decades, and a generation that experienced a low nutritional environment during fetal life due to poverty and/or political turmoil has now shifted to a life of excess (Figure 2). Therefore, they are expected to have acquired the 'thrifty phenotype' in utero and now encounter a 'mismatch' of excess energy supply due to calorie-rich diets, thereby increasing the risk of NCDs associated with obesity and/or type 2 diabetes (Figure 1,2).

In Japan, obesity has increased among adult males as well as mature and senile women, whereas undernourishment is common among women of childbearing age due to their strong desire to be thin, ${ }^{33)}$ concomitant with an increase in low birth weight neonates. ${ }^{32,34,35)}$ The mean total caloric intake of the Japanese population has continuously decreased since $1970,{ }^{32,34)}$ indicating that the incidence of obesity has increased in spite of the intake of fewer calories. This paradoxical and rapid shift towards an obesity-prone phenotype in a relatively short period (i.e., less than half a century) in middle-aged and 


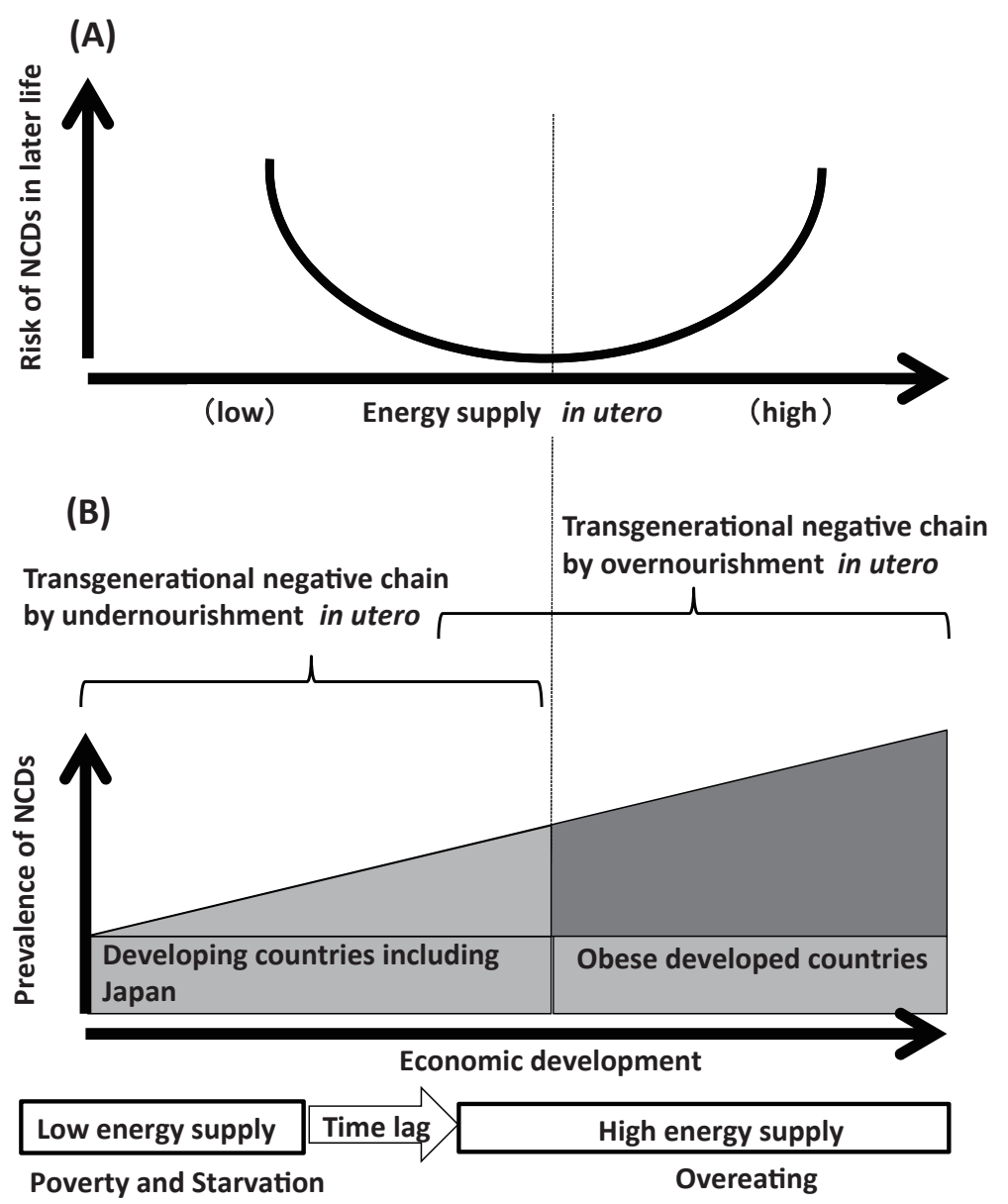

Figure 2. Energy supply in utero and the risk of NCDs in later life (A). The prevalence of NCDs in both developing and developed countries may be associated with differences in energy supply in utero (B).

elderly Japanese populations argues against the simple and major contribution of a Western lifestyle with a calorie-rich diet in favor of a presumed increase in the number of individuals with the 'thrifty phenotype' due to undernourishment in utero. Kubota et al. ${ }^{36)}$ reported that the mean energy intake in Japanese pregnant women was less than 1,600 kilocalories/day throughout pregnancy, which corresponds to $30 \%$ (second trimester) and $37 \%$ (third trimester) fewer calories than what is recommended by the Ministry of Health, Labour and Welfare Japan (Figure 3). This suggests that considerable numbers of relatively undernourished Japanese fetuses exist due to a shortage in maternal energy intake. This distinct nutritional imbalance in Japanese pregnant women may have led to the 'thrifty phenotype' in a large number of Japanese people, contributing, at least partly, to the development of obesity and or type 2 diabetes with less caloric intake. ${ }^{35}$ ) Therefore, the nutritional conditions of Japanese fetuses are distinct from those in other developed countries, in which fetuses are typically supplied with excess energy from their mothers.

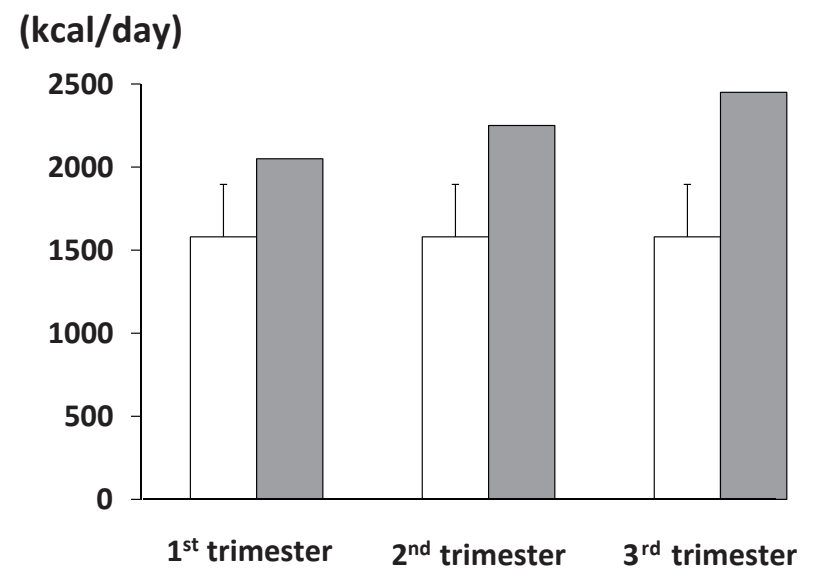

Figure 3. Mean energy intake of Japanese pregnant women in Hamamatsu city (white bars) and recommended energy intake by the Health, Labour and Welfare Ministry of Japan (gray bars). ${ }^{36)}$

Error bars indicate standard deviations. 


\section{'Hypothalamic-adipose (HA) axis' hypothesis concerning 'thrifty phenotype'}

The mechanisms underlying the 'thrifty phenotype' have not yet been elucidated in detail; however, large numbers of animal models have provided evidence to support its involvement in calorie-rich countries. ${ }^{37,38)}$ Hales and Barker proposed that the permanently reduced secretion of insulin from pancreatic $\beta$-cells is critically involved in the development of an adult 'thrifty phenotype' concomitant with insulin resistance. ${ }^{24)}$ Newsome et al. ${ }^{39)}$ conclusively proposed a relationship between low birth weight and disorders in glucose and insulin metabolism in adulthood by a systematic review of the literature. However, the early-programmed reduced secretion of insulin does not coincide with the initial induction of obesity in later life because adipocytes require an appropriate amount of insulin to store lipids. Therefore, the fetal insulin hypothesis cannot fully explain the primary risk of obesity proposed by the 'thrifty phenotype' hypothesis.

Since the 'mismatch' of the 'thrifty phenotype' with an abundant energy supply may result in excess energy storage in the body, reasonably in adipose tissue, it is plausible that obesity is the most acceptable outcome of exposing 'thrifty phenotype' offspring to a calorierich diet. Moreover, obesity is a major risk factor for NCDs. ${ }^{40)}$ Therefore, in this review, we focused on the developmental origins of obesity in relation to the 'thrifty phenotype', particularly in the context of the central regulation of energy metabolism, and introduced our 'hypothalamic-adipose (HA) axis' hypothesis as a candidate mechanism for explaining the acquisition of the 'thrifty phenotype'.

Obesity is closely associated with the regulation of food intake and energy expenditure, which are centrally regulated by the hypothalamus, the control center for energy metabolism. The adipocyte-derived hormone, leptin, is known to affect the hypothalamus, leading to a decrease in food intake and increase in energy expenditure. ${ }^{41,42)}$ Disruptions in the production and circulating levels of leptin have been shown to play an important role in the development of metabolic syndrome in adulthood. ${ }^{41)}$ Evidence obtained in animal studies supported undernourishment in utero causing low hypothalamic sensitivity to circulating leptin, thereby linking undernourishment in utero to the risk of obesity in later life. ${ }^{43}$ Moreover, maternal caloric restriction did not exacerbate obesity in leptin-deficient $o b / o b$ mice, suggesting that leptin is a key factor in the developmental origins of obesity. ${ }^{44)}$ We previously revealed that undernourishment in utero resulted in blunted responses in food intake by and lower body weights in adult mice treated with leptin, concomitant with low signal transduction responses in the hypothalamus, relative to normally nourished controls. ${ }^{45)}$ We also showed that chemical damage to the arcuate nucleus (ARC) of the hypothalamus canceled out the accelerated development of obesity in adult mouse offspring that were undernourished in utero. ${ }^{45)}$ Since the ARC, which centrally regulates energy expenditure, ${ }^{46}$ ) has been proposed to be the main target of leptin, permanent changes in hypothalamic responsiveness to circulating leptin appear to be the main regulatory system in the developmental risk of adult obesity, at least in our mouse animal model of undernourishment in utero.

Serum leptin levels markedly increase in normal mouse neonates during the lactation period, and this is referred to as the 'leptin surge ${ }^{47)}$ (Figure 4A). However, previous studies reported that leptin did not affect feeding or thermogenesis in neonatal mice ${ }^{48)}$ or rats. ${ }^{49)}$ Bouret et al. $^{50)}$ reported that the neurotrophic action of leptin in the mouse hypothalamus only operated during the neonatal period. $\mathrm{We}^{44,45)}$ and others ${ }^{51,52)}$ proposed that undernourishment in utero changed the timing and/or plasma levels of leptin in the 'leptin surge' during the period of lactation and modified the development of neuronal circuitries in the hypothalamus, resulting in permanently low hypothalamic responses to circulating leptin and thereby increasing the risk of obesity (Figure 4B). However, changes in the 'leptin surge' during the neonatal period and its permanent effects on adulthood
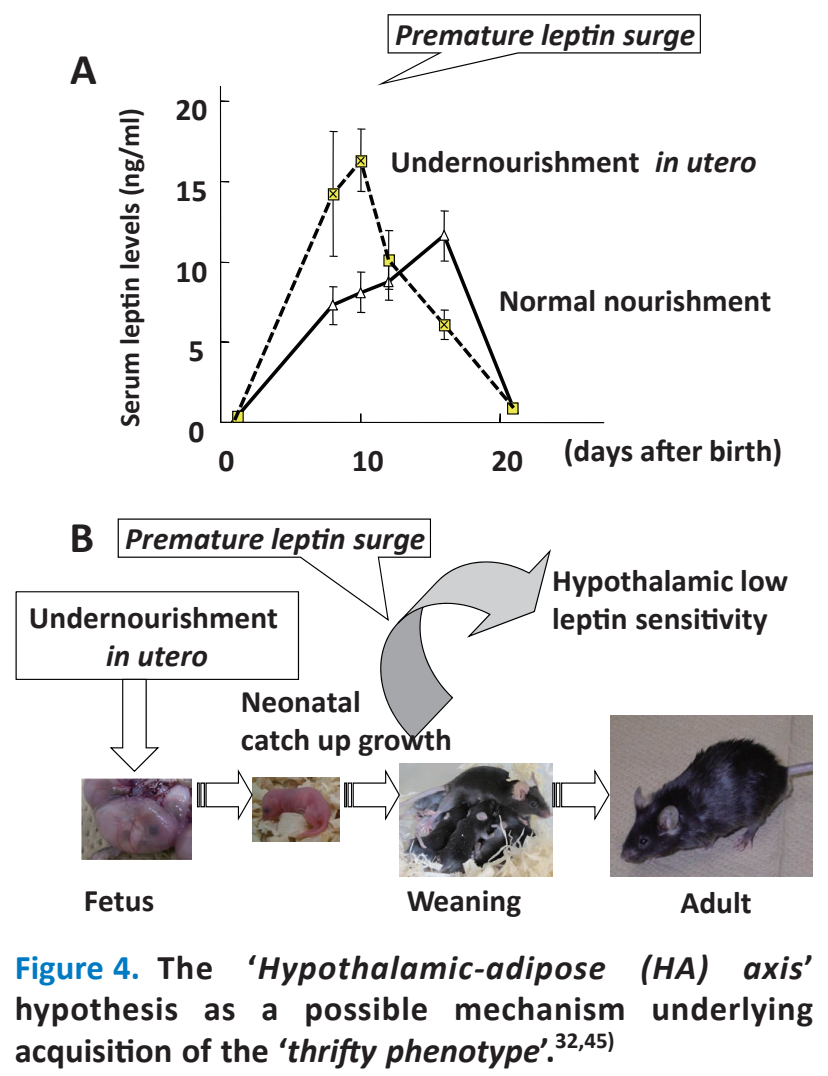
remain controversial. We previously demonstrated that a $30 \%$ restriction in maternal caloric intake $(70 \%$ of $a d$ libitum intake) in the latter half of pregnancy caused earlier and greater deviations in the 'leptin surge' in neonates, which we described as a 'premature leptin

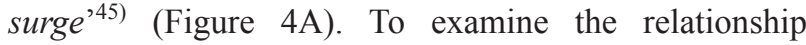
between the 'premature leptin surge' and the risk of adult obesity, we administrated leptin to normally-nourished male mice aged 5 to 10 days and found that these pups subsequently developed a similar obesity-prone phenotype and low hypothalamic sensitivity to leptin as pups undernourished in utero, concomitant with similar changes in the development of neuronal circuitries in the hypothalamus. ${ }^{45)}$ These findings suggested a distinct role for the 'premature leptin surge' as a programming signal from adipose tissue to the hypothalamus. De Moura et al. ${ }^{52)}$ also reported that the treatment of neonatal rats with leptin, either from 0 to 10 days of age or in the last 10 days of the lactation period, led to obesity and high leptin concentrations in later life.

On the other hand, Delahaye et al. ${ }^{51)}$ reported that a $50 \%$ restriction in caloric intake by rats from pregnancy to the lactation period markedly decreased the 'leptin surge'. Vickers et al. ${ }^{53)}$ administered leptin to rat neonates from 3 to 10 days and found no phenotypic changes in normally nourished pups, but protection against obesity in pups undernourished in utero. To the best of our knowledge, there is currently no clear explanation for this discrepancy and we speculate the presence of multifactorial 'critical windows' in exposure of the hypothalamus to the 'leptin surge' during the lactation period with respect to timing, duration, dosage of the leptin treatment in each experimental protocol, gender differences, and species differences even between rats and mice. Nevertheless, changes in plasma leptin concentrations during the lactation period induced by fetal undernourishment, although still contentious, appear to be a key modulator of permanent hypothalamic energy regulation, leading to the development of the obesity-prone adult phenotype. Based on our findings, we proposed the important contribution of the ' $H A$ axis' hypothesis to the developmental origins of obesity (Figure 4B).

\section{'Hypothalamic-pituitary-adrenal (HPA) axis' hypothesis and NCDs}

The hypothalamus is not only the center of energy metabolism, but also a central regulator of stress responses that down-regulate the secretion of glucocorticoids from the adrenal glands, i.e., the hypothalamic-pituitaryadrenal (HPA) axis. A shift to an elevated stress response has been closely linked with the risk of NCDs. ${ }^{54-57)}$ The findings of previous clinical and molecular studies

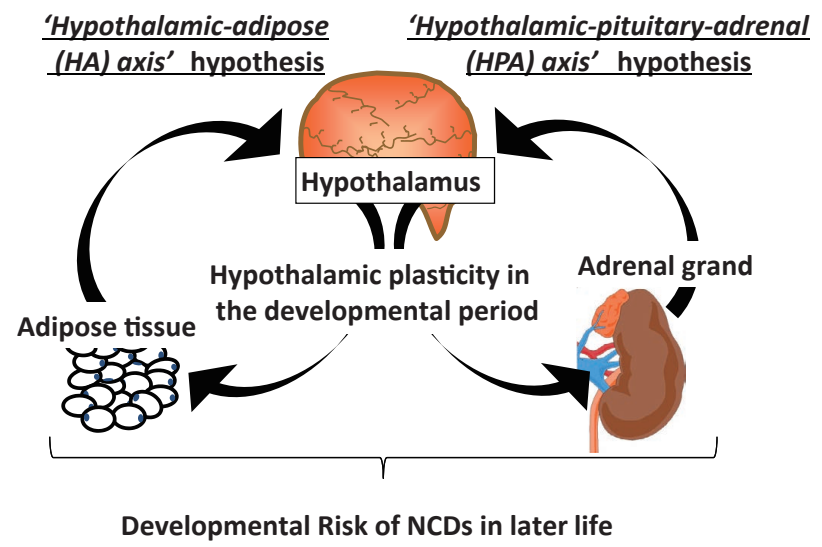

Figure 5. Hypothalamic plasticity in early life and developmental risk of NCDs in later life. ${ }^{32)}$

demonstrated that elevated levels of adrenal hormones caused the accumulation of fat in visceral adipose tissues as well as associated metabolic abnormalities. ${ }^{58,59)}$ Human and animal studies indicated that prenatal stress caused the permanent hyper-reactivity of the HPA axis to be causatively associated with an elevated risk of NCDs; namely, the 'HPA axis' hypothesis ${ }^{60-68)}$ (Figure 5).

Morphological and functional hypothalamic plasticity during the early developmental period has been suggested to play a key role in the 'HPA axis' and ' $H A$ axis' hypotheses (Figure 5); therefore, the hypothalamus appears to be a promising target organ in the search for new early interventions that will reduce the prevalence of NCDs.

\section{Accumulation of NCD risk by 'catch-up growth'}

A systematic review revealed that small babies were more predisposed to adult obesity if they showed rapid 'catch-up growth' soon after birth ${ }^{69)}$ (Figure 1). Regarding the critical period of 'catch-up growth', previous studies suggested the possible importance of the first few weeks of postnatal life $\mathrm{e}^{70,71)}$ or the period until two years of age ${ }^{69)}$ whereas others showed that low birth weight children who grew excessively in later childhood were also at a higher risk of adult obesity. ${ }^{21,72)}$ Botton et al. ${ }^{73)}$ showed that neonates with a faster weight gain velocity during the first three months showed a greater weight gain velocity after three years of age, leading to a larger fat mass in adolescence (Figure 6). These findings suggested that the interaction between prenatal low energy supply and subsequent rapid 'catch up growth' soon after birth, presumably being equal to a rapid encounter with a postnatal high-energy supply, appeared to increase the risk of obesity and its associated metabolic disorders ${ }^{31,38,74-76)}$ (Figure 1). 


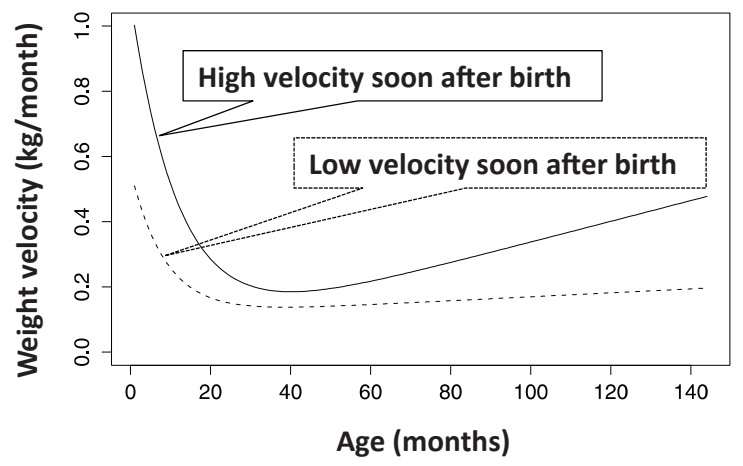

Figure 6. Predicted transition of weight growth velocity (modified from the figure by Botton et al.) ${ }^{73}$ )

\section{'Catch-up-related adipose tissue remodeling' hypothesis concerning accumulation of NCD risk by 'catch-up growth'}

To the best of our knowledge, a consensus has not yet been reached regarding how 'catch-up growth' soon after birth increases the risk of adult obesity caused by undernourishment in utero, or how it permanently modulates the metabolic characteristics of the 'thrifty phenotype' acquired by undernourishment in utero. We recently focused on the possible involvement of adipose tissue remodeling in the aggravation of obesity-related metabolic disorders by 'catch-up growth' during the lactation period.

The fat body of drosophila evolved into three different organs, i.e., adipose tissue, liver, and blood cells of mammals, over a period of 60 million years, during which the reciprocal regulation of their functions developed. ${ }^{77)}$ Recent studies identified various changes in the intercellular spaces between ballooning adipocytes due to increased lipid storage, particularly those associated with the chronic infiltration of immune competent cells, especially inflammatory macrophages, leading to the concomitant impairment of glucose and/or lipid metabolism. ${ }^{78-80}$ ) We recently developed a mouse animal model of undernourishment in utero by maternal caloric restriction, in which the rate of 'catch-up growth' during the lactation period positively correlated with

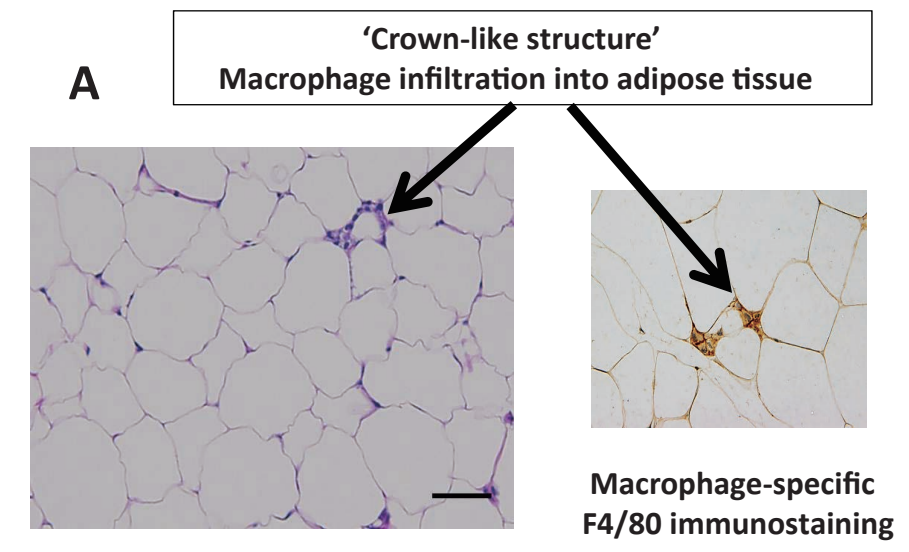

HE staining

B

M1 macrophage infiltration

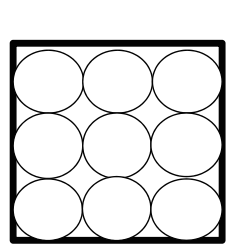

Simple obesity

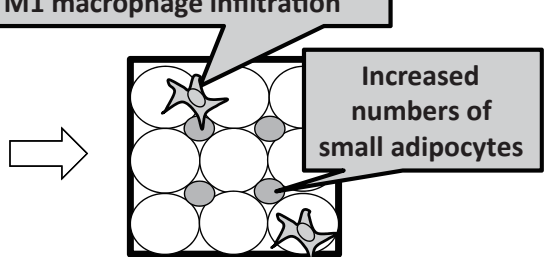

Adipose tissue remodeling with chronic inflammation

\begin{tabular}{ll} 
Undernourishment & \\
in utero & Positive correlation with catch up \\
\cline { 2 - 2 } Normal & \\
nourishment & No association with catch up \\
\cline { 2 - 2 }
\end{tabular}

Figure 7. 'Catch-up-related adipose tissue remodeling' hypothesis for increased risk of obesity and associated metabolic disorders by 'catch-up growth'. ${ }^{81,84)}$ 
body weight gain, fat mass gain, and blood glucose levels under a high fat diet. ${ }^{81)}$ Using this animal model, we demonstrated that the rate of 'catch-up growth' after undernourishment in utero positively correlated with the infiltration of M1 macrophages (Figure 7A) as well as the expression of inflammatory cytokines in adult adipose tissue collected from mice on a high fat diet. ${ }^{81)}$ These findings indicated that rapid growth during the lactation period, attributed to a rich-energy supply following low-energy supply in utero, appeared to induce chronic inflammation in adult adipose tissue ${ }^{81)}$ (Figure 7A, B). Fetal undernourishment also increased the number of not only large, but also small ballooning adipocytes in adult adipose tissue obtained from mice on a high fat diet. ${ }^{81)}$ Nishimura et al. ${ }^{82)}$ proposed that small adipocytes, which are adipogenic/angiogenic cell clusters including adipocyte precursor cells, play a major role in adipocyte hyperplasia, and are prominent during the development of obesity; therefore, the concept of 'adipose tissue remodeling' was proposed as a critical pathological mechanism underlying the exacerbation of obesity itself and its related metabolic disorders. ${ }^{79,83)}$ We previously reported that the rate of 'catch-up growth' during the lactation period positively correlated with the relative rate of small adipocytes in adult adipose tissue collected from animals on a high fat diet ${ }^{81)}$ suggesting that 'catch-up growth' induced 'adipose tissue remodeling' (Figure 7B). These findings indicated that a sudden change in nutritional conditions from a low energy supply in utero to a calorie-rich neonatal life, leading to 'catch-up growth', is a key phenomenon exaggerating 'adipose tissue remodeling' based on chronic inflammation in later life (Figure 7B). Therefore, we proposed the 'catchup-related adipose tissue remodeling' hypothesis ${ }^{84)}$ as a potential mechanism for the risk accumulation of NCDs by 'catch-up growth'.

\section{Overnourishment in utero and risk of NCDs in later life}

The incidence of obesity has increased in developed countries, especially in North America, over the past several decades due to the oversupply of nutrients relative to the amount required for normal metabolism. This increase can be largely attributed to lifestyle patterns such as the excess consumption of energy-rich meals and decline in physical activity. However, an alternative explanation has been proposed for the increasing rates of obesity, i.e., a transgenerational negative chain of overnourishment in utero and/or the postnatal period (Figure 2). The DOHaD theory states that infants subjected to an early environment that is over-rich in nutrients are predisposed to obesity in later life (Figure 2).
Fetal exposure to diabetes or gestational diabetes during pregnancy has been reported to increase the risk of childhood and adult obesity, diabetes, metabolic syndrome, and cardiovascular diseases. ${ }^{85,86)}$ In a cohort study involving the Pima Indians, the majority of whom develop type 2 diabetes during childhood due to genetic causes, the risk of type 2 diabetes and obesity was higher in the fetuses of diabetic mothers. ${ }^{87)}$ Previous studies identified a relationship between maternal obesity and excessive weight gain during pregnancy and large-forgestational-age infants. ${ }^{88-91)}$ Furthermore, the risk of childhood and adolescent obesity was found to be higher in these large-for-gestational-age infants. ${ }^{88,91,92)}$ Salsberry et al. $^{93)}$ showed that maternal pre-pregnancy obesity was a significant risk factor for overweight adolescent offspring. Human and animal studies revealed that a high intrauterine energy supply consistently elevated the risk of NCDs in later life. ${ }^{94-96)}$ In developed countries, especially those in which obesity appears to be prevalent, the transgenerational risk of early exposure to an excess energy supply in the intrauterine environment has been proposed to play a crucial role in increasing the risk of NCDs in addition to overeating and reduced physical activity. Although mankind battled against starvation for millions of years, those in developed countries need to adapt to a continuous environment of satiation throughout life from in utero.

Since undernourishment in utero is also a risk factor for NCDs in later life, a 'U-shaped' curve was proposed for the relationship between nutritional conditions in utero and the risk of developing adult $\mathrm{NCDs}^{3,25,26,31,38,97,98)}$ (Figure 2). The rate of increase in the number of NCD patients in developing countries is markedly higher than that in developed countries; ${ }^{3,98)}$ therefore, overnourishment after birth may be a stronger risk factor for the development of adult NCDs in neonates undernourished in utero than the continuous exposure to overnourishment over the entire course of life, including the fetal period.

\section{Candidates for early interventions in perinatal medicine}

The core concepts of preemptive medicine are the early identification of high-risk individuals and early interventions specific to the risk background. ${ }^{8,999)}$ Although evidence for the preventive efficacy of early interventions against the continuing prevalence of NCDs as well as medical economic cost performance is limited, we proposed the following candidates as targets for early interventions in perinatal medicine (Figure 8). Nutritional interventions for lean and obese pregnant women, if effective, represent the most promising strategy ${ }^{100,101)}$ (Figure 8) due to the high 


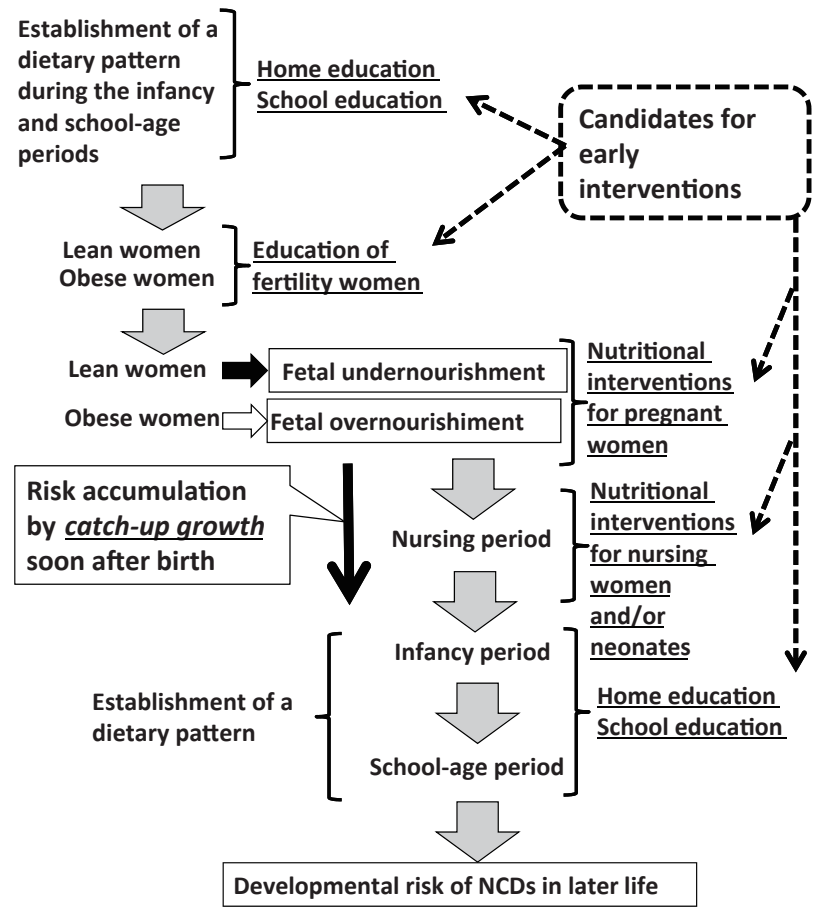

Figure 8. Candidates for early interventions in preemptive medicine from the standpoint of perinatal care.

risk of undernourishment and overnourishment in utero, respectively. Educational interventions concerning nutritional aspects for fertile women, including information on the transgenerational negative chain according to the DOHaD theory, ${ }^{3,25,26,31,38,97,98)}$ before conception may effectively reduce the incidence of lean and obese pregnant women (Figure 8). Considering the establishment of dietary patterns during infancy and school-age periods, and preparing and conducting home and school educational programs on lifestyle based on scientific evidence, especially lifelong benefits, while also taking into consideration the next generation, will be constructive (Figure 8).

Since 'catch-up growth' has been reported to increase the risk of adult NCDs, ${ }^{21,31,38,69-76)}$ nutritional interventions for nursing women and/or neonates may be another target for early interventions (Figure 8). However, Houk et al. ${ }^{102)}$ demonstrated that children born small for gestational age without 'catch-up growth' were at high risk of short stature in adulthood and should be referred for growth hormone treatment. Therefore, deciding the neonatal and infantile optimal growth patterns in view of differing genetic and epigenetic backgrounds due to environmental factors for the purpose of improving lifelong outcomes is difficult. Furthermore, establishing standard methods to achieve optimal growth in neonates and/or infants is challenging because numerous factors, including various unidentified ones, may be involved in their growth patterns. It is also important to respect the natural wishes of mothers to have normal children, especially if they were born small. The development of home and school educational programs concerning the importance of improving the lifestyles of children who experience 'catch-up growth' would be beneficial (Figure 8).

\section{Candidate biological samples for identifying biomarkers in perinatal medicine}

The final goal of preemptive medicine is to delay or prevent the onset of NCDs by identifying high-risk individuals in early life and implementing early interventions specific to their risk types. ${ }^{8,999)}$ Barker et al. ${ }^{103)}$ first proposed that low birth weight newborns (i.e., those weighing less than 2,500 g) were at high risk of developing cardiovascular diseases in later life. According to the 'U-shaped' curve observation $^{3,25,26,31,38,97,98)}$ (Figure 2), macrosomia is also a risk factor for NCDs. ${ }^{104)}$ The rates of low birth weight and macrosomia in Japan were reported to be $9.6 \%$ and $0.5 \%$, respectively. ${ }^{105)}$ In contrast, the rate of macrosomia in the United States was $10 \%{ }^{106)}$ Thus, birth weight varies greatly by region and historical transition. Furthermore, because of the considerable contribution of genetic background and other factors, such as preterm deliveries, multiple pregnancies, maternal complications, fetal complications, and placental deficiencies, small and large babies are not always solely the result of undernourishment and overnourishment in utero, respectively. Therefore, the simple assessment of birth weight is not sufficiently specific for clear identification of high-risk individuals.

Substantial efforts have been made over the past few decades to identify effective biomarkers for use in clinical practice that can identify individuals at high risk of developing NCDs. ${ }^{107-112)}$ The application of "omics" technologies to biological samples has identified hundreds to thousands of biomarker candidates; however, only a small number of these have been translated into clinical diagnostics for patient care and/or early interventions for premorbid patients. ${ }^{111,112)}$ Gupta et al. ${ }^{112)}$ primarily attributed this to disease heterogeneity and preanalytical variabilities associated with the identification of biomarkers, and also, in developing countries, to economic crises, a lack of awareness and education, the paucity of biorepositories, enormous diversity in socio-epidemiological backgrounds, ethnicity, lifestyles, diet, exposure to various environmental risk factors and infectious agents, and ethical and social issues.

We propose the following biological samples for use in identifying biomarkers in individuals at high risk of 


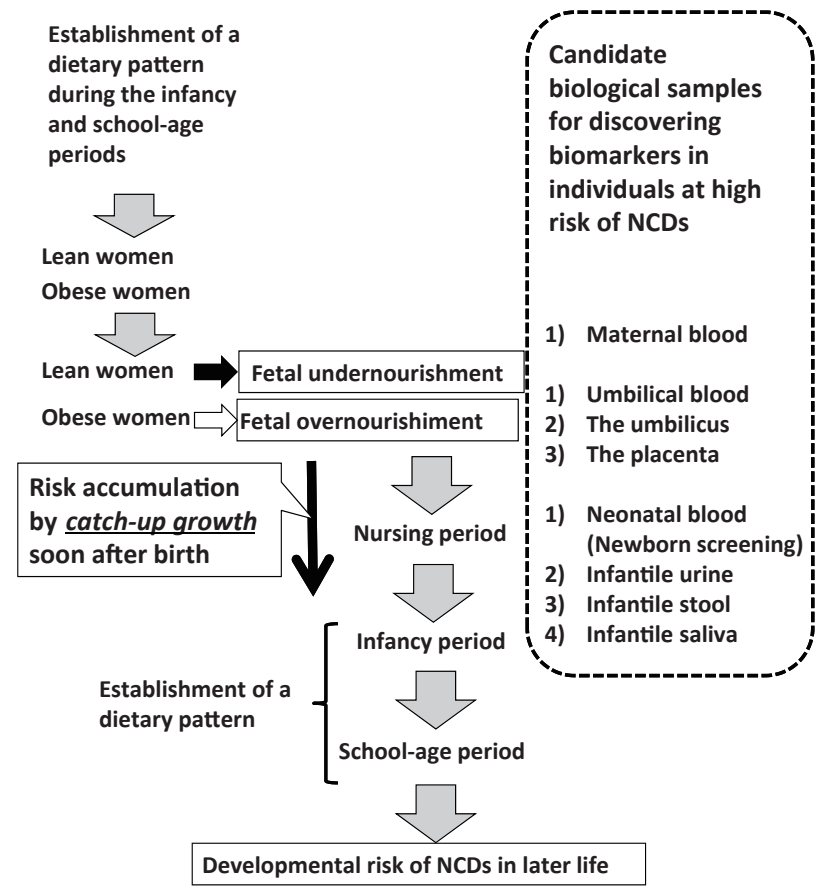

Figure 9. Candidate biological samples for the identification of biomarkers from the standpoint of perinatal care.

developing NCDs from the standpoint of perinatal care (Figure 9): 1) blood samples from pregnant women (cell-free fetal DNA), ${ }^{113,114)}$ 2) umbilical blood, 3) the umbilicus (pure fetal origin tissue), 4) the placenta (mostly fetal origin tissue, but including maternal origin tissue, especially in the basal plate of the placenta), 5) neonatal blood obtained at a newborn screening, such as Guthrie newborn screening, ${ }^{115)}$ 6) infantile urine, 7) infantile stools, and 8) infantile saliva.

Inexpensive and simple standard methodologies using stable biological samples that are easy to access need to be established in order to identify individuals at high risk of developing NCDs using newly identified biomarkers because the prevalence of NCDs is a heavy burden not only in developed, but also in developing countries. The road from the identification of effective biomarkers, authorization, and governmental approval to their translation into clinical settings appears to be long and difficult; however, the rewards may be significant not only for individuals, but also for society because lowering the morbidity of NCDs will reduce medical expenses and social security costs and ensure an effective workforce in the future.

\section{Conclusions}

The morbidity of NCDs has increased rapidly in both developing and developed countries, leading to substantial increases in health care and social security costs. In view of the pathogenesis of NCDs based on the $\mathrm{DOHaD}$ theory, the perinatal care of fetuses as well as neonates has an important impact on the risk of NCDs in adulthood. The importance of perinatal care is expected to be reconsidered from the perspective of preemptive medicine.

\section{Acknowledgments}

This work was supported in part by Grants-in-aid for Scientific Research from the Ministry of Education, Culture, Sports, Science, and Technology, Japan (No. 24390273, No. 25670490). The authors thank Mrs. Yumiko Yamamoto, Mrs. Naoko Kondo, Mrs. Kazuko Sugiyama, and Mrs. Miuta Sawai for their secretarial and technical assistance.

\section{Conflict of interest}

None.

\section{References}

1. World Health Organization. ed. Global status report on noncommunicable diseases 2010 Description of the global burden of NCDs, their risk factors and determinants. 2010. Available from URL: http://www.who.int/nmh/publications/ ncd_report2010/en/.

2. Noncommunicable disease. 2013. Available from URL: http:// www.who.int/mediacentre/factsheets/fs $355 / \mathrm{en} /$.

3. Katz AR. Noncommunicable diseases: global health priority or market opportunity? An illustration of the World Health Organization at its worst and at its best. Int J Health Serv. 2013; 43: 437-458.

4. Gluckman PD, Hanson MA. Living with the past: evolution, development, and patterns of disease. Science. 2004; 305: $1733-$ 1736.

5. Gluckman PD, Hanson MA. eds. Developmental Origins of Health and Disease. Cambridge: Cambridge University Press, 2006.

6. Hanson M, Godfrey KM, Lillycrop KA, Burdge GC, Gluckman PD. Developmental plasticity and developmental origins of noncommunicable disease: theoretical considerations and epigenetic mechanisms. Prog Biophys Mol Biol. 2011; 106: 272-280.

7. Barouki R, Gluckman PD, Grandjean P, Hanson M, Heindel JJ. Developmental origins of non-communicable disease: implications for research and public health. Environ Health. 2012; 11: 42 .

8. Imura H. Life course health care and preemptive approach to non-communicable diseases. Proc Jpn Acad Ser B Phys Biol Sci. 2013; 89: 462-473.

9. Strategic Vision for the Future-From Curative to Pre-emptive Medicine. 2011. Available from URL: http://www.nih.gov/ strategicvision.htm

10. Silveira PP, Portella AK, Goldani MZ, Barbieri MA. Developmental origins of health and disease (DOHaD). J Pediatr 
(Rio J). 2007; 83: 494-504.

11. Hanson MA, Gluckman PD. Developmental origins of health and disease-Global public health implications. Best Pract Res Clin Obstet Gynaecol. 2015; 29: 24-31.

12. Ravelli AC, van Der Meulen JH, Osmond C, Barker DJ, Bleker OP. Obesity at the age of $50 \mathrm{y}$ in men and women exposed to famine prenatally. Am J Clin Nutr. 1999; 70: 811-816.

13. Roseboom T, de Rooij S, Painter R. The Dutch famine and its long-term consequences for adult health. Early Hum Dev. 2006; 82: 485-491.

14. Kyle UG, Pichard C. The Dutch Famine of 1944-1945: a pathophysiological model of long-term consequences of wasting disease. Curr Opin Clin Nutr Metab Care. 2006; 9: 388-394.

15. Li Y, He Y, Qi L, et al. Exposure to the Chinese famine in early life and the risk of hyperglycemia and type 2 diabetes in adulthood. Diabetes. 2010; 59: 2400-2406.

16. Zheng X, Wang Y, Ren W, et al. Risk of metabolic syndrome in adults exposed to the great Chinese famine during the fetal life and early childhood. Eur J Clin Nutr. 2012; 66: 231-236.

17. Li Y, Jaddoe VW, Qi L, et al. Exposure to the chinese famine in early life and the risk of metabolic syndrome in adulthood. Diabetes Care. 2011; 34: 1014-1018.

18. Malina RM, Katzmarzyk PT, Beunen G. Birth weight and its relationship to size attained and relative fat distribution at 7 to 12 years of age. Obes Res. 1996; 4: 385-390.

19. Okosun IS, Liao Y, Rotimi CN, Dever GE, Cooper RS. Impact of birth weight on ethnic variations in subcutaneous and central adiposity in American children aged 5-11 years. A study from the Third National Health and Nutrition Examination Survey. Int J Obes Relat Metab Disord. 2000; 24: 479-484.

20. Law CM, Barker DJ, Osmond C, Fall CH, Simmonds SJ. Early growth and abdominal fatness in adult life. J Epidemiol Community Health. 1992; 46: 184-186.

21. Eriksson J, Forsén T, Tuomilehto J, Osmond C, Barker D. Size at birth, childhood growth and obesity in adult life. Int J Obes Relat Metab Disord. 2001; 25: 735-740.

22. Kensara OA, Wootton SA, Phillips DI, Patel M, Jackson AA, Elia M. Fetal programming of body composition: relation between birth weight and body composition measured with dual-energy X-ray absorptiometry and anthropometric methods in older Englishmen. Am J Clin Nutr. 2005; 82: 980-987.

23. Mühlhäusler BS, Adam CL, McMillen IC. Maternal nutrition and the programming of obesity: The brain. Organogenesis. 2008; 4: 144-152.

24. Hales CN, Barker DJ. The thrifty phenotype hypothesis. Br Med Bull. 2001; 60: 5-20.

25. Prentice AM, Moore SE. Early programming of adult diseases in resource poor countries. Arch Dis Child. 2005; 90: 429-432.

26. Prentice AM, Rayco-Solon P, Moore SE. Insights from the developing world: thrifty genotypes and thrifty phenotypes. Proc Nutr Soc. 2005; 64: 153-161.

27. Gluckman PD, Hanson MA. eds. The Fetal Matrix-Evolution, Development and Disease- Cambridge: Cambridge University Press, 2005.

28. Moore SE, Halsall I, Howarth D, Poskitt EM, Prentice AM. Glucose, insulin and lipid metabolism in rural Gambians exposed to early malnutrition. Diabet Med. 2001; 18: 646-653.

29. Gluckman PD, Hanson MA. eds. Mismatch. Oxford: Oxford University Press, 2006.
30. Gluckman PD, Hanson MA. Developmental and epigenetic pathways to obesity: an evolutionary-developmental perspective. Int J Obes (Lond). 2008; 32 (suppl 7): S62-71.

31. Fernandez-Twinn DS, Ozanne SE. Mechanisms by which poor early growth programs type-2 diabetes, obesity and the metabolic syndrome. Physiol Behav. 2006; 88: 234-243.

32. Itoh H, Kanayama N. Low birth weight and risk of obesity - Potential Problem of Japanese People- Current Women's Health Reviews. 2009; 5: 212-219.

33. Hayashi F, Takimoto H, Yoshita K, Yoshiike N. Perceived body size and desire for thinness of young Japanese women: a population-based survey. Br J Nutr. 2006; 96: 1154-1162.

34. Goto Y. Diseases in the 21st century. Journal of Japan Society for the Study of Obesity. 2006; 12: 1-2. (In Japanese.)

35. Gluckman PD, Seng CY, Fukuoka H, Beedle AS, Hanson MA. Low birthweight and subsequent obesity in Japan. Lancet. 2007; 369: 1081-1082.

36. Kubota $\mathrm{K}$, Itoh $\mathrm{H}$, Tasaka $\mathrm{M}$, et al. Changes of maternal dietary intake, bodyweight and fetal growth throughout pregnancy in pregnant Japanese women. J Obstet Gynaecol Res. 2013; 39: 1383-1390.

37. Jones RH, Ozanne SE. Fetal programming of glucose-insulin metabolism. Mol Cell Endocrinol. 2009; 297: 4-9.

38. Taylor PD, Poston L. Developmental programming of obesity in mammals. Exp Physiol. 2007; 92: 287-298.

39. Newsome CA, Shiell AW, Fall CH, Phillips DI, Shier R, Law CM. Is birth weight related to later glucose and insulin metabolism? -A systematic review. Diabet Med. 2003; 20: 339-348.

40. Webber L, Divajeva D, Marsh T, et al. The future burden of obesity-related diseases in the 53 WHO European-Region countries and the impact of effective interventions: a modelling study. BMJ Open. 2014; 4: e004787.

41. Flier JS. Obesity wars: molecular progress confronts an expanding epidemic. Cell. 2004; 116: 337-350.

42. Friedman JM. Obesity in the new millennium. Nature. 2000; 404: 632-634.

43. Dulloo AG. Thrifty energy metabolism in catch-up growth trajectories to insulin and leptin resistance. Best Pract Res Clin Endocrinol Metab. 2008; 22: 155-171.

44. Yura S, Itoh H, Sagawa N, et al. Neonatal exposure to leptin augments diet-induced obesity in leptin-deficient $\mathrm{Ob} / \mathrm{Ob}$ mice. Obesity (Silver Spring). 2008; 16: 1289-1295.

45. Yura S, Itoh H, Sagawa N, et al. Role of premature leptin surge in obesity resulting from intrauterine undernutrition. Cell Metab. 2005; 1: 371-378.

46. Könner AC1, Klöckener T, Brüning JC. Control of energy homeostasis by insulin and leptin: Targeting the arcuate nucleus and beyond. Physiol Behav. 2009; 97: 632-638.

47. Ahima RS, Prabakaran D, Flier JS. Postnatal leptin surge and regulation of circadian rhythm of leptin by feeding. Implications for energy homeostasis and neuroendocrine function. J Clin Invest. 1998; 101: 1020-1027.

48. Mistry AM, Swick A, Romsos DR. Leptin alters metabolic rates before acquisition of its anorectic effect in developing neonatal mice. Am J Physiol. 1999; 277: R742-747.

49. Proulx K, Richard D, Walker CD. Leptin regulates appetiterelated neuropeptides in the hypothalamus of developing rats without affecting food intake. Endocrinology. 2002; 143: 46834692. 
50. Bouret SG, Draper SJ, Simerly RB. Trophic action of leptin on hypothalamic neurons that regulate feeding. Science. 2004; 304: $108-110$.

51. Delahaye F, Breton C, Risold PY, et al. Maternal perinatal undernutrition drastically reduces postnatal leptin surge and affects the development of arcuate nucleus proopiomelanocortin neurons in neonatal male rat pups. Endocrinology. 2008;149: $470-475$.

52. de Moura EG, Lisboa PC, Passos MC. Neonatal programming of neuroimmunomodulation-role of adipocytokines and neuropeptides. Neuroimmunomodulation. 2008; 15: 176-188.

53. Vickers MH, Gluckman PD, Coveny AH, et al. Neonatal leptin treatment reverses developmental programming. Endocrinology. 2005; 146: 4211-4216.

54. Masuzaki H, Paterson J, Shinyama H, et al. A transgenic model of visceral obesity and the metabolic syndrome. Science. 2001; 294: 2166-2170.

55. Masuzaki H, Yamamoto H, Kenyon CJ, et al. Transgenic amplification of glucocorticoid action in adipose tissue causes high blood pressure in mice. J Clin Invest. 2003; 112: 83-90.

56. Morton NM, Seckl JR. 11beta-hydroxysteroid dehydrogenase type 1 and obesity. Front Horm Res. 2008; 36: 146-164.

57. Vicennati V, Garelli S, Rinaldi E, Di Dalmazi G, Pagotto U, Pasquali R. Cross-talk between adipose tissue and the HPA axis in obesity and overt hypercortisolemic states. Horm Mol Biol Clin Investig. 2014; 17: 63-77.

58. Björntorp P. Do stress reactions cause abdominal obesity and comorbidities? Obes Rev. 2001; 2: 73-86.

59. Rosmond R, Dallman MF, Björntorp P. Stress-related cortisol secretion in men: relationships with abdominal obesity and endocrine, metabolic and hemodynamic abnormalities. J Clin Endocrinol Metab. 1998; 83: 1853-1859.

60. Kapoor A, Dunn E, Kostaki A, Andrews MH, Matthews SG. Fetal programming of hypothalamo-pituitary-adrenal function: prenatal stress and glucocorticoids. J Physiol. 2006; 572: 31-44.

61. Phillips DI, Jones A. Fetal programming of autonomic and HPA function: do people who were small babies have enhanced stress responses? J Physiol. 2006; 572: 45-50.

62. Matthews SG, Owen D, Kalabis G, et al. Fetal glucocorticoid exposure and hypothalamo-pituitary-adrenal (HPA) function after birth. Endocr Res. 2004; 30: 827-836.

63. Seckl JR, Cleasby M, Nyirenda MJ. Glucocorticoids, 11betahydroxysteroid dehydrogenase, and fetal programming. Kidney Int. 2000; 57: 1412-1417.

64. Seckl JR, Holmes MC. Mechanisms of disease: glucocorticoids, their placental metabolism and fetal 'programming' of adult pathophysiology. Nat Clin Pract Endocrinol Metab. 2007; 3: 479-488.

65. Seckl JR, Meaney MJ. Glucocorticoid programming. Ann N Y Acad Sci. 2004; 1032: 63-84.

66. Weaver IC, Cervoni N, Champagne FA, et al. Epigenetic programming by maternal behavior. Nat Neurosci. 2004; 7 : $847-854$.

67. Weinstock M. The potential influence of maternal stress hormones on development and mental health of the offspring. Brain Behav Immun. 2005; 19: 296-308.

68. Kajantie E. Fetal origins of stress-related adult disease. Ann N Y Acad Sci. 2006; 1083: 11-27.

69. Ong KK, Loos RJ. Rapid infancy weight gain and subsequent obesity: systematic reviews and hopeful suggestions. Acta Paediatr. 2006; 95: 904-908.

70. Stettler N, Kumanyika SK, Katz SH, Zemel BS, Stallings VA. Rapid weight gain during infancy and obesity in young adulthood in a cohort of African Americans. Am J Clin Nutr. 2003; 77: 1374-1378.

71. Stettler N, Stallings VA, Troxel AB, et al. Weight gain in the first week of life and overweight in adulthood: a cohort study of European American subjects fed infant formula. Circulation. 2005; 111: 1897-1903.

72. Rolland-Cachera MF, Deheeger M, Bellisle F, Sempe M, Guilloud-Bataille M, Patois E. Adiposity rebound in children: a simple indicator for predicting obesity. Am J Clin Nutr. 1984; 39: 129-135.

73. Botton J, Heude B, Maccario J, Ducimetiere P, Charles MA. Postnatal weight and height growth velocities at different ages between birth and $5 \mathrm{y}$ and body composition in adolescent boys and girls. Am J Clin Nutr. 2008; 87: 1760-1768.

74. Berends LM, Fernandez-Twinn DS, Martin-Gronert MS, Cripps RL, Ozanne SE. Catch-up growth following intra-uterine growthrestriction programmes an insulin-resistant phenotype in adipose tissue. Int J Obes (Lond). 2013; 37: 1051-1057.

75. Bol VV, Delattre AI, Reusens B, Raes M, Remacle C. Forced catch-up growth after fetal protein restriction alters the adipose tissue gene expression program leading to obesity in adult mice. Am J Physiol Regul Integr Comp Physiol. 2009; 297: R291-299.

76. Gonzalez-Bulnes A, Ovilo C, Lopez-Bote CJ, et al. Genderspecific early postnatal catch-up growth after intrauterine growth retardation by food restriction in swine with obesity/leptin resistance. Reproduction. 2012; 144: 269-278.

77. Hotamisligil GS. Inflammation and metabolic disorders. Nature. 2006; 444: 860-867.

78. Lee MJ, Wu Y, Fried SK. Adipose tissue remodeling in pathophysiology of obesity. Curr Opin Clin Nutr Metab Care. 2010; $13: 371-376$.

79. Sun K, Kusminski CM, Scherer PE. Adipose tissue remodeling and obesity. J Clin Invest. 2011; 121: 2094-2101.

80. Suganami T, Mieda T, Itoh M, Shimoda Y, Kamei Y, Ogawa Y. Attenuation of obesity-induced adipose tissue inflammation in $\mathrm{C} 3 \mathrm{H} / \mathrm{HeJ}$ mice carrying a Toll-like receptor 4 mutation. Biochem Biophys Res Commun. 2007; 354: 45-49.

81. Kohmura YK, Kanayama N, Muramatsu K, et al. Association between body weight at weaning and remodeling in the subcutaneous adipose tissue of obese adult mice with undernourishment in utero. Reprod Sci. 2013; 20: 813-827.

82. Nishimura S, Manabe I, Nagasaki M, et al. Adipogenesis in obesity requires close interplay between differentiating adipocytes, stromal cells, and blood vessels. Diabetes. 2007; 56: $1517-1526$.

83. Suganami T, Tanaka M, Ogawa Y. Adipose tissue inflammation and ectopic lipid accumulation. Endocr J. 2012; 59: 849-857.

84. Itoh H. Adipocytokine, fetal growth, and DOHaD. Hormone Frontier in Gynecology. 2014; 21: 59-66. (In Japanese.)

85. Clausen TD, Mathiesen ER, Hansen T, et al. Overweight and the metabolic syndrome in adult offspring of women with diet-treated gestational diabetes mellitus or type 1 diabetes. J Clin Endocrinol Metab. 2009; 94: 2464-2470.

86. Moore TR. Fetal exposure to gestational diabetes contributes to subsequent adult metabolic syndrome. Am J Obstet Gynecol. 
2010; 202: 643-649.

87. Dabelea D, Pettitt DJ. Intrauterine diabetic environment confers risks for type 2 diabetes mellitus and obesity in the offspring, in addition to genetic susceptibility. J Pediatr Endocrinol Metab. 2001; 14: 1085-1091.

88. American College of Obstetricians and Gynecologists. ACOG Committee opinion no. 549: obesity in pregnancy. Obstet Gynecol. 2013; 121: 213-217.

89. Cedergren MI. Maternal morbid obesity and the risk of adverse pregnancy outcome. Obstet Gynecol. 2004; 103: 219-224.

90. Rode L, Nilas L, Wojdemann K, Tabor A. Obesity-related complications in Danish single cephalic term pregnancies. Obstet Gynecol. 2005; 105: 537-542.

91. Hediger ML, Overpeck MD, McGlynn A, Kuczmarski RJ, Maurer KR, Davis WW. Growth and fatness at three to six years of age of children born small- or large-for-gestational age. Pediatrics. 1999; 104: e33.

92. Sebire NJ, Jolly M, Harris JP, et al. Maternal obesity and pregnancy outcome: a study of 287,213 pregnancies in London. Int J Obes Relat Metab Disord. 2001; 25: 1175-1182.

93. Salsberry PJ, Reagan PB. Taking the long view: the prenatal environment and early adolescent overweight. Res Nurs Health. 2007; 30: 297-307.

94. Armitage JA, Poston L, Taylor PD. Developmental origins of obesity and the metabolic syndrome: the role of maternal obesity. Front Horm Res. 2008; 36: 73-84.

95. Dyer JS, Rosenfeld CR. Metabolic imprinting by prenatal, perinatal, and postnatal overnutrition: a review. Semin Reprod Med. 2011; 29: 266-276.

96. Li M, Sloboda DM, Vickers MH. Maternal obesity and developmental programming of metabolic disorders in offspring: evidence from animal models. Exp Diabetes Res. 2011; 2011: 592408.

97. Curhan GC, Willett WC, Rimm EB, Spiegelman D, Ascherio $\mathrm{AL}$, Stampfer MJ. Birth weight and adult hypertension, diabetes mellitus, and obesity in US men. Circulation. 1996; 94: 32463250.

98. Prentice AM. Nutrition and chronic disease: lessons from the developing and developed world. Nestle Nutr Inst Workshop Ser. 2014; 78: $155-160$.

99. Agboola SO, Ball M, Kvedar JC, Jethwani K. The future of Connected Health in preventive medicine. QJM. 2013; 106: 791-794.

100. Kulkarni B, Kuper H, Radhakrishna KV, et al. The association of early life supplemental nutrition with lean body mass and grip strength in adulthood: evidence from APCAPS. Am J Epidemiol.
2014; 179: 700-709.

101. Tanvig M. Offspring body size and metabolic profile - effects of lifestyle intervention in obese pregnant women. Dan Med J. 2014; 61: B4893.

102. Houk CP, Lee PA. Early diagnosis and treatment referral of children born small for gestational age without catch-up growth are critical for optimal growth outcomes. Int J Pediatr Endocrinol. 2012; 2012: 11.

103. Barker DJ, Osmond C. Infant mortality, childhood nutrition, and ischaemic heart disease in England and Wales. Lancet. 1986; 1: 1077-1081.

104. Ornoy A. Prenatal origin of obesity and their complications: Gestational diabetes, maternal overweight and the paradoxical effects of fetal growth restriction and macrosomia. Reprod Toxicol. 2011; 32: 205-212.

105. Maternal and Child Health Statistics of Japan. Tokyo: Mother's \& Children's Health Organization, 2013.

106. Ventura SJ, Martin JA, Curtin SC, Mathews TJ, Park MM. Births: final data for 1998. Natl Vital Stat Rep. 2000; 48: 1-100.

107. Paulovich AG, Whiteaker JR, Hoofnagle AN, Wang P. The interface between biomarker discovery and clinical validation: The tar pit of the protein biomarker pipeline. Proteomics Clin Appl. 2008; 2: 1386-1402.

108. Zhang Z, Chan DW. The road from discovery to clinical diagnostics: lessons learned from the first FDA-cleared in vitro diagnostic multivariate index assay of proteomic biomarkers. Cancer Epidemiol Biomarkers Prev. 2010; 19: 2995-2999.

109. Michiels S, Kramar A, Koscielny S. Multidimensionality of microarrays: statistical challenges and (im)possible solutions. Mol Oncol. 2011; 5: 190-196.

110. Füzéry AK, Levin J, Chan MM, Chan DW. Translation of proteomic biomarkers into FDA approved cancer diagnostics: issues and challenges. Clin Proteomics. 2013; 10: 13.

111. Gomez-Cabrero D, Abugessaisa I, Maier D, et al. Data integration in the era of omics: current and future challenges. BMC Syst Biol. 2014; 8 (suppl 2): I1.

112. Gupta S, Venkatesh A, Ray S, Srivastava S. Challenges and prospects for biomarker research: a current perspective from the developing world. Biochim Biophys Acta. 2014; 1844: 899-908.

113. Taglauer ES, Wilkins-Haug L, Bianchi DW. Review: cell-free fetal DNA in the maternal circulation as an indication of placental health and disease. Placenta. 2014; 35 (suppl): S64-68.

114. Lo JO, Cori DF, Norton ME, Caughey AB. Noninvasive prenatal testing. Obstet Gynecol Surv. 2014; 69: 89-99.

115. Baston H. The Guthrie test. Midwifery basics. Pract Midwife. 2002; 5: 32-35. 